\title{
pnmbalina
}

(8)

\section{A Universidade de Coimbra no cardápio da Cosinha Portugueza de 1902: uma história por contar}

\author{
Autor(es): $\quad$ Soares, Carmen \\ Publicado por: Imprensa da Universidade de Coimbra \\ URL \\ persistente: URI:http://hdl.handle.net/10316.2/43689 \\ DOI: $\quad$ DOI:https://doi.org/10.14195/978-989-26-1364-2_4 \\ Accessed : $\quad$ 26-Apr-2023 15:13:28
}

A navegação consulta e descarregamento dos títulos inseridos nas Bibliotecas Digitais UC Digitalis, UC Pombalina e UC Impactum, pressupõem a aceitação plena e sem reservas dos Termos e Condições de Uso destas Bibliotecas Digitais, disponíveis em https://digitalis.uc.pt/pt-pt/termos.

Conforme exposto nos referidos Termos e Condições de Uso, o descarregamento de títulos de acesso restrito requer uma licença válida de autorização devendo o utilizador aceder ao(s) documento(s) a partir de um endereço de IP da instituição detentora da supramencionada licença.

Ao utilizador é apenas permitido o descarregamento para uso pessoal, pelo que o emprego do(s) título(s) descarregado(s) para outro fim, designadamente comercial, carece de autorização do respetivo autor ou editor da obra.

Na medida em que todas as obras da UC Digitalis se encontram protegidas pelo Código do Direito de Autor e Direitos Conexos e demais legislação aplicável, toda a cópia, parcial ou total, deste documento, nos casos em que é legalmente admitida, deverá conter ou fazer-se acompanhar por este aviso.

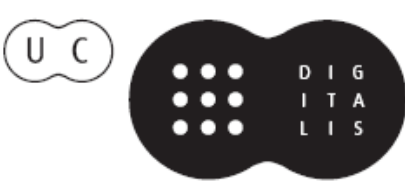




\section{BIBLIOALIMENTARIA}

Alimentação, Saúde e Sociabilidade à Mesa no acervo bibliográfico da Universidade de Coimbra

Carmen Soares (Coord.)
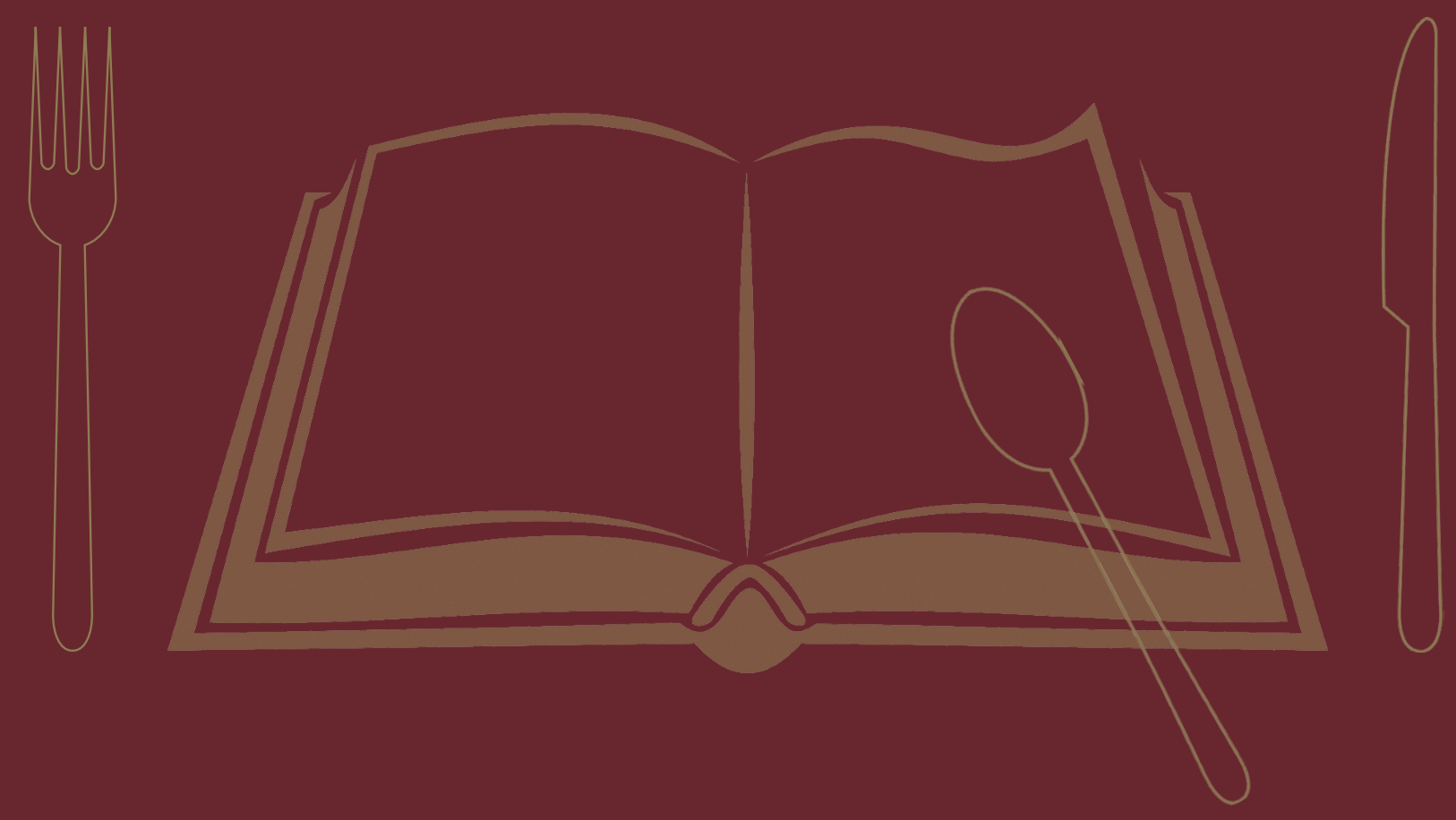

Imprensa da Universidade de Coimbra

Coimbra University Press 


\section{A Universidade de Coimbra}

\section{no cardápio da Cosinba}

\section{Portugueza de 1902: uma}

\section{história por contar}

Carmen Soared

Foi em Coimbra que, em 1902, se publicou a $2 .^{a}$ edição do primeiro livro de cozinha nacional portuguesa, Cosinha Portugueza, que inclui cinco receitas com títulos evocativos da Academia de Coimbra. A obra resultou do contributo literário de diversas senhoras da cidade ou a ela ligadas, uma vez que se publica sob a chancela de uma instituição benemérita da paróquia conimbricense de Santo António dos Olivais.

Volvidos pouco mais de 100 anos (uma vez que desconhecemos a data da $1 .^{\text {a }}$ ed. da obra), revelamos e analisamos o sentido da inclusão nesta obra não só de um pequeno núcleo de receitas dadas como identitárias da Universidade de Coimbra, mas também o porquê de virem incluídas naquele que é o primeiro livro de culinária português a cunhar na capa a sua filiação nacionalista. Assim estruturámos a nossa análise em torno de 4 eixos temáticos:

1. História da publicação da Cosinha Portugueza;

2. Contributos da Cosinha Portugueza para a história da sociedade portuguesa sua contemporânea;

3. O discurso culinário nacionalista na Cosinba Portugueza;

4. "Iguarias académicas": a presença da "culinária honorífica" na formação do património alimentar nacional.

\section{História da publicação da Cosinha Portuguesa}

Iniciaremos o nosso estudo por apresentar os elementos que conseguimos apurar sobre a história da Cosinba Portuguesa ou
Arte Culinária Nacional e preliminares annexos. 2. ${ }^{a}$ edição muito melhorada. Colaboração de Senhoras. Imprensa Académica. Coimbra 1902 (cat. n. ${ }^{\circ}$ 10).

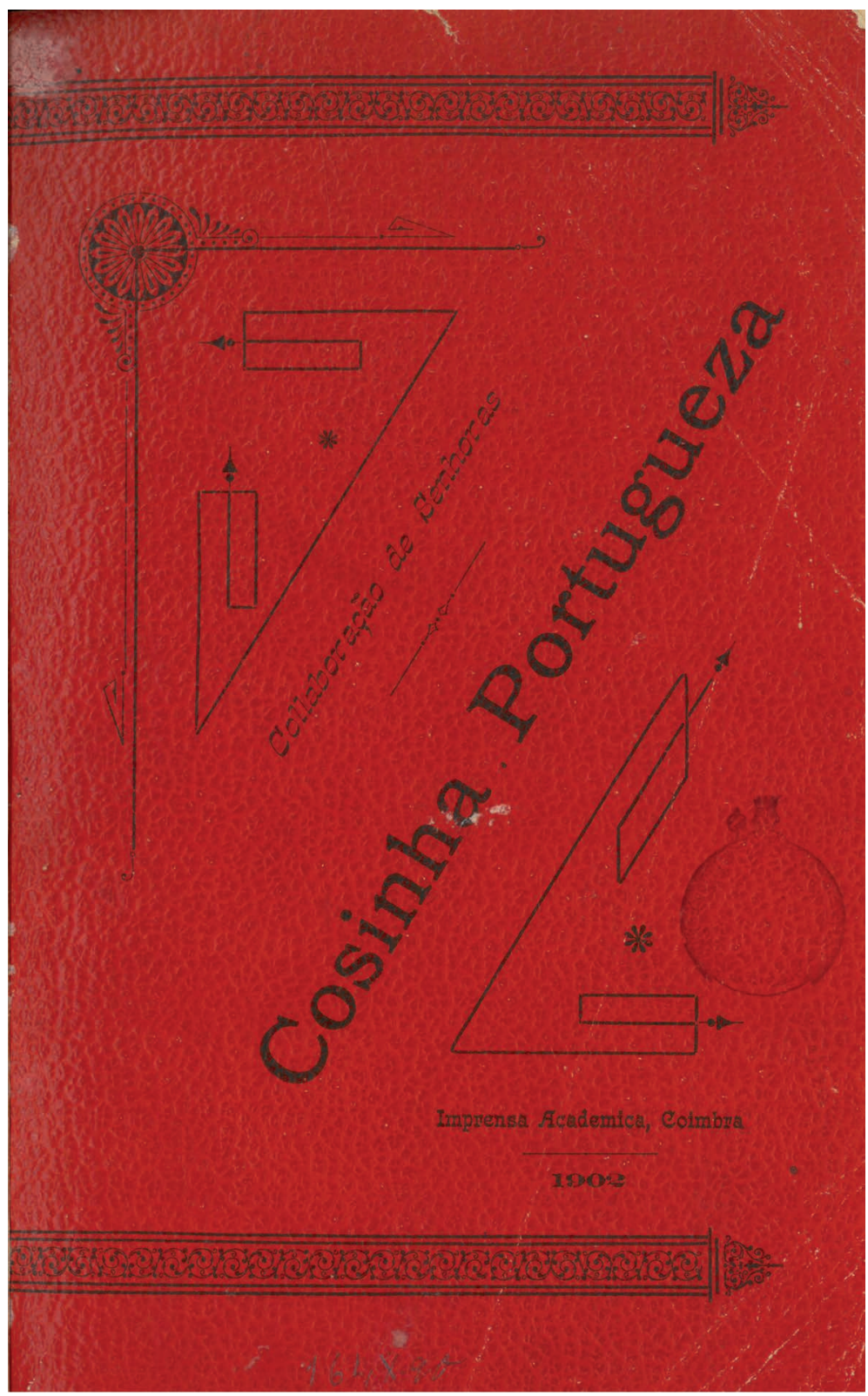

Esta matéria desde o início se nos afigurou uma empresa para a qual deveríamos contar com a colaboração de um verdadeiro especialista na genealogia do livro, o técnico bibliotecário e arquivista. Recorremos, de imediato, à prestimosa colaboração 
da Dra. Ana Maria Bandeira, rosto da parceria do AUC na iniciativa BiblioAlimentaria. Foi graças ao seu labor verdadeiramente "detectivesco" que pudemos atar algumas das pontas soltas desta reconstituição do percurso de montagem e publicação do livro.

O livro de cozinha em análise é uma publicação promovida por e "propriedade" de um núcleo do Instituto Pão de Santo António, com sede em Olivais, "freguesia sub-urbana da cidade de Coimbra". Receamos por isso, que, como sucedeu em muitas outras situações, devido aos "apagamentos de memória" que, sob o efeito devastador das mudanças do Regime Monárquico Constitucional para a República, levaram à supressão de documentação eclesiástica, não venhamos a encontrar a documentação escrita que nos poderia dar respostas seguras às seguintes perguntas: qual a identidade do Editor? Quem foram essas Senhoras que enviaram as receitas compiladas na obra? Como era constituído, quais as regras de funcionamento e atividades desse núcleo católico franciscano de benemerência e qual o período de existência nos Olivais?

Até à data apenas pudemos apurar que o Instituto Pão de Santo António dos Olivais foi um dos vários núcleos existentes em Portugal do "Pão dos Pobres de Santo António", florescente durante o século XIX um pouco por toda a Europa (França, Bélgica, Itália e Alemanha). A sua sede no nosso país foi instituída em Braga, no ano de 1895, pela comunidade do Convento de Montariol $^{135}$. O Administrador do Pão era um cargo que devia ser exercido por um membro da Ordem Terceira e o organismo de fins piedosos e caritativos admitia "todas as pessoas de bons costumes e de vontade caritativa"136.

Caberia interrogarmo-nos se, por ventura, o anónimo editor do nosso livro não seria esse administrador, logo um religioso. Sem elementos que nos permitam proceder a afirmações seguras a este respeito, não podemos deixar de observar que alguns indícios apontam no sentido de se tratar de um indivíduo do sexo masculino, com prática editorial, declaradamente desconhecedor

\section{Araújo 1995.}

136 Citação de Gomes (2007-2008: 476), que continua: "e segundo os relatórios de gestão, o número de inscritos em fins de 1901, de todas as regiões, era de 142.069". da literatura culinária, mas com certeza familiarizado com as publicações de preceitos e ensinamentos filosófico-morais. Repare-se que, se, por um lado, foi uma decisão sua, para a qual reclama autoridade própria, incluir em "appendice" (que na 2. edição passa à posição dianteira de "preliminares"), "algumas reflexões de ordem moral”, que “julgámos que não era fóra de propósito publicar” (p. XI), pelo outro, após mencionar as partes da obra relativas aos preceitos de economia doméstica e de receituário, não pode deixar de confessar que "se viu muito fóra da ordem de trabalhos a que costuma aplicar a sua actividade" (p. XII).

Retomando as informações relativas à entidade proprietária do livro, refira-se que nas igrejas os fundos das "caixas de esmolas" do Pão de Santo António, quando abertas, destinavam-se, como o próprio nome sugere, antes de mais a fornecer aos carenciados a base da sua dieta alimentar, o pão. As palavras do editor da Cosinha Portugueza, em rubrica inicial, extraída da 1. ${ }^{a}$ edição e na qual se apresenta o "Motivo da publicação" (p. vII), revelam mais pormenores não só sobre os principais destinos dos donativos em dinheiro recolhidos, mas também sobre a "logística" financeira envolvente. Os primeiros destinatários privilegiados do pecúlio oferecido são um sector bem definido do grupo indeterminado do termo "pobres", os patriarcas que, circunstancialmente (por motivo de doença ou desamparo total), estejam incapacitados de prover ao sustento da família e não aufiram qualquer outro apoio público caritativo (p. viII). Neste caso, o fundo fornece-lhes o "socorro" das necessidades básicas de alimentação e vestuário, assim como lhes permite fazer frente a outro tipo de gastos, já que, além de pão e de roupas, pode oferecer dinheiro.

A esse contingente, que tem necessariamente de merecer a primeira menção, uma vez que é o chefe de família o alicerce incontestado da sociedade, junta o autor outras "categorias" de necessitados, por comparação com aquele, hierarquicamente inferiores: "os entrevados, os desvalidos e as viúvas" (p. XI). Fica, assim, completo o retrato dos pobres a que se destina o auxílio do Instituto Pão de Santo António.

Sabe-se que as esmolas, recolhidas em duas caixas para o efeito (a das Petições e a dos Despachos), por uma questão de 
segurança, iam sendo regularmente retiradas e depositadas na “Caixa Económica Portugueza”, instituição bancária sob a tutela do Estado (criada em 1880), destinada a incentivar a poupança, compensada com a retribuição de juros anuais aos depositantes ${ }^{137}$.

Restaurar a antiga (e muito arruinada) cela onde Santo António tomou o hábito franciscano, convertida em capela do convento de Franciscanos dos Olivais em Coimbra, é uma obra seguramente "piedosa" (como se lê na folha de rosto da obra e se explica na "Motivação da publicação", p. VII), mas que só subsidiariamente recorreria ao fundo do Instituto Pão de Santo António ${ }^{138}$. Ou seja, como se lê no texto, em havendo "sobras" do fundo das caixas de esmolas do Pão dos Pobres, esta verba seria usada para outros fins. Daí que a obra franciscana tenha, como desenvolveremos abaixo, provavelmente por sugestão das Senhoras que a integravam e muito em particular da esposa do proprietário da casa editora, a Imprensa Académica de Coimbra, lançado mão de uma campanha especialmente destinada ao "fim piedoso" de restaurar a capela de Santo António, a publicação de um livro de culinária. Com esta iniciativa editorial presta-se cumulativamente um serviço à Igreja e, como desenvolveremos no ponto seguinte, às famílias portuguesas, fortalecendo as suas identidades culinárias coletivas.

Sabe-se, ainda, que à frente da paróquia nesse ano de 1902 estava o Padre Manuel Feliciano Dias ${ }^{139}$. Um indício interessante sobre uma eventual "relação de proximidade" entre quem publica (a Imprensa Académica) e quem edita (o Instituto do Pão de

137 Cf. informação disponível online, da autoria de Helena Real (Gabinete do Património Histórico da Caixa Geral de Depósitos), aqui: https:/www.cgd. $\mathrm{pt} /$ Institucional/Patrimonio-Historico-CGD/Estudos/Documents/Criacao-da-Caixa-Economica-Portuguesa.pdf. Para um estudo sobre as Caixas Económicas em Portugal, vd. Sameiro (2011). Segundo o autor, a primeira caixa económica portuguesa foi a Caixa Económica de Lisboa (fundada em 1844), correspondente à atual Caixa Económica Montepio Geral.

138 Nas palavras iniciais do livro, o editor confirma que à data de publicação da 2. ${ }^{a}$ edição, ou seja, em 1902, as obras já estavam bastante adiantadas, o que lhe permite projetar a inauguração da "capella-cella" (p. viII) para o ano seguinte, 1903.

139 Cf. Livro de registo paroquial de Santo António dos Olivais, C44 (1902): cota AUC-III-1. ${ }^{2}$ D (código de referência PT/AUC/PAR(CBR18/003/0044).
Santo António dos Olivais) pode surpreender-se em informações biográficas sobre o proprietário da casa editora. Através da consulta da escritura de constituição de sociedade da "Imprensa Académica" (datada de 22 de janeiro de 1906) ${ }^{140}$, gerida pela firma social de Araújo Pinto \& Teixeira de Abreu, ficamos a saber que, nesta data, era já D. Angelina Beatriz de Loureiro Araújo Pinto, viúva do Dr. Ruben Augusto de Almeida Araújo Pinto, por herança do marido, a proprietária da empresa, até aí pertença apenas da sua família (desde a sua fundação, em 1870).

Sobre esta família Araújo Pinto, o Inventário Orfanológico constituído por morte do patriarca (em 1903 e só terminado em 1915), informa que o seu local de residência era em Santo António dos Olivais ${ }^{141}$. Atando algumas destas pontas soltas, não é improvável supor que como "boa dona de casa" e "senhora" da sociedade burguesa coimbrã, a esposa do proprietário da Imprensa Académica, sita na Rua da Sofia (153-165), tenha tido envolvimento direto na promoção da edição da obra. Assim o "exigia" o código moral de piedade devota, inerente ao seu estatuto social (assunto que retomaremos abaixo, no ponto 2), e tornava "natural e expectável" o negócio do marido.

Em suma, não sabemos os nomes das diversas "senhoras" que colaboraram com o envio das suas receitas para a composição deste primeiro livro de cozinha portuguesa, mas temos fortes indícios sobre uma das figuras femininas que poderá ter desempenhado um papel determinante na génese editorial da obra: D. Angelina Beatriz de Loureiro Araújo Pinto, esposa do então proprietário da Imprensa Académica.

Para finalizar estas considerações sobre a história da publicação da obra, é com grande pesar que lamentamos não ter conseguido acesso a nenhum vol. da 1. ${ }^{a}$ edição, cuja data tão pouco conseguimos apurar. Apenas sabemos que foi um sucesso de vendas, tendo-se esgotado em menos de três meses os seus 1200 exemplares, o que proporcionou o aparecimento de uma 2. ${ }^{a}$ edição. Desses seus

140 Cf. Notário de Coimbra - Joaquim Alves de Faria, liv. 54, fl. 28v - cota AUC-V-1. ${ }^{\mathrm{a}} \mathrm{E}-14-4-71$.

141 Agradecemos à Dra. Ana Maria Bandeira ter-nos fornecido todos estes elementos levantados de documentação depositada no AUC. 
esclarecimentos preliminares (p. XII), depreendemos que o Editor procedeu a uma nova disposição da ordem de aparecimento das receitas e dos "preliminares". Estes, que na $1^{\text {a }}$ ed. figuravam como anexo, aparecendo no final do livro, depois das receitas, passaram, agora, para a abertura da obra. Se tivermos em linha de conta o teor das reflexões contidas nesses "preliminares" (ensinamentos sobre moral e filosofia de vida cristãs, seguidos de guia prático de preceitos de habitação, água, vestuário e diversos), torna-se evidente o peso que a mentalidade catequizadora da instituição proponente assume na "mensagem" que a obra encerra.

A ausência de conhecimento da 1. a edição inviabiliza um exercício particularmente interessante em termos do que era a conceção de "culinária nacional”, uma vez que ficámos impossibilitadas de confrontar o receituário dessa com o que nos chegou. A curiosidade em relação a um estudo comparativo fica assaz aguçada, quando lemos na folha de rosto da obra a indicação: " $2 .^{\text {a }}$ edição muito melhorada".

\section{Contributos da Cosinha Portugueza PARA A história DA} SOCIEDADE PORTUGUESA SUA CONTEMPORÂNEA

Conforme percebemos pelos contornos acima delineados da história da conceção e produção do livro, a Cosinha Portugueza permite-nos refletir em especial sobre o papel da mulher na esfera privada e pública. Ainda que sob a capa do anonimato e subordinada à potestas da liderança masculina (do marido ou do padre), a mulher-esposa, senhora e dona de casa, tem uma competência modeladora e formativa que derruba as fronteiras do seu lar. No século xıx, num período em que a "moda" culinária da corte, da aristocracia e da alta burguesia continuava a ser maioritariamente ditada pelos gostos internacionais das cozinhas francesa e italiana (de restaurantes, grandes cozinheiros e livros de culinária impressos), assiste-se simultaneamente a uma tendência oposta a esta, patente na literatura realista de oitocentos, de que um exemplo maior será o romance $A$ cidade e as serras de Eça de Queirós. Como bem sublinhou recentemente Ana Teresa
Peixinho, nesta obra é particularmente evidente a afirmação da identidade portuguesa pela sua gastronomia típica, em confronto com a sofisticada (mas estrangeira) baute cuisine française, estratégia literária ao serviço da oposição entre autenticidade e imitação deturpada ${ }^{142}$. Ou seja, assiste-se, na segunda metade do século XIX, a afloramentos do interesse de (alguma elite) pela cozinha simples e plebeia. Sobretudo (e esse é um fenómeno de reação frequente face à globalização dos gostos em diferentes momentos históricos) o primeiro livro de cozinha portuguesa vem no prefácio fundamentado num desígnio educativo urgente: “instruir a família na proveitosa arte de cosinha portugueza”. Não restam, por conseguinte, dúvidas de que o predomínio das influências estrangeiras nos cardápios dos livros impressos em Portugal desde o século XVII atingira um ponto de saturação. Os ideais nacionalistas acesos ainda no século XVIII, com a Revolução Francesa, inflamam-se ao longo do século xix (e de um modo muito particular, durante o século xx, no período conhecido por Estado Novo) e serviram de rastilho para, também no setor da literatura culinária, aparecer o primeiro livro hasteando a bandeira nacionalista portuguesa.

Não estranhemos que a Igreja, a quem os valores tradicionais sempre serviram de âncora ideológica, seja a promotora da publicação da Cosinha Portugueza. Tanto mais que esta serve dois princípios determinantes para combater o anticlericalismo frequente entre os homens das elites: a ação social caritativa e a missão pedagógica de formação da família. As palavras recuperadas da 1. edição são, como vimos acima, bastante claras a respeito dessa dupla motivação (formativa e caritativa) da obra. O título da epígrafe dedicatória do livro - "Às boas donas de casa" - não podia ser mais apropriado. São elas, as mães e esposas, as fiéis depositárias dessa instrução familiar e doméstica que é a arte da culinária nacional. Por outro lado a obra tem a vantagem de permitir acumular um "producto" (i. e., o quantitativo das vendas),

142 Peixinho 2016: 211. Sobre os significados da presença da gastronomia na obra queirosiana, vd. também os estudos de Alves 1992, Berrini 1995, Berrini-Modesto 2014, Vilela 2010. 
destinado a um ato de benemerência "piedosa", condizente com os princípios da obra do "Pão de Santo António".

Transpira destes esclarecimentos introdutórios do editor do livro toda uma série de elementos sobre o papel da mulher na sociedade portuguesa do século XIX, já estudados com grande profundidade e rigor histórico em obras coletivas e individuais de referência no panorama da História das Mulheres e da Vida Quotidiana, de que destaco os trabalhos de Irene Vaquinhas ${ }^{143}$. Do ponto de vista do género literário dos livros de cozinha, esta obra integra-se numa categoria com enorme expressão editorial nas culturas anglo-americana e hispano-americana, os chamados “community/compiled/re-funding cookbooks". São obras que compilam receitas oferecidas por senhoras de uma determinada comunidade, maioritariamente de perfil religioso, cuja venda reverta para obras filantrópicas ou de recuperação/construção de edifícios ${ }^{144}$.

Importa ter presente que as indicações de que o público-alvo era o padrão feminino da boa dona de casa e, simultaneamente, de que foram senhoras as autoras e/ou transmissoras do receituário compilado no livro são dois indícios inequívocos de que estamos perante um produto criado por e para a mulher burguesa e não para a mulher do povo ${ }^{145}$. Ou seja, enquanto aquela é a gestora de

\section{Vaquinhas 2000, 2005 e 2011.}

144 Vd. para a realidade americana, com o aparecimento do género a dar-se nos anos da Guerra da Secessão (1861-1865), os estudos de Lynne (1981) e Bower (1997). Segundo Scott (1992), o modelo foi posteriormente levado para a Argentina e Peru por mestres de escola americanas. Pilcher (1999: 211) aponta como fim caritativo de livros de culinária publicados com receitas de senhoras católicas mexicanas precisamente obras em duas catedrais da Cidade do México. Veja-se para a realidade britânica e suas colónias o estudo de Leong-Salobir (2014: 135).

145 Essa distinção entre a mulher nascida e criada no seio da "gente de bem" (a senhora) e a que pertence ao povo (a mulher) corresponde, como bem sublinha Vaquinhas (2000: 15), a uma estratégia de distanciamento social desenvolvida pela burguesia. Os Códigos de civilidade e periódicos como Almanach das Senhoras são dois bons exemplos de como nesse século Xıx, e por iniciativa das próprias mulheres (como é o caso do referido periódico, fundado por Guiomar Torrezão), o mercado editorial orientado para o público feminino veiculava e ajudava a enraizar todo um código de valores comportamentais e éticos diferenciador de hierarquias entre o género feminino. Note-se que é num artigo desse almanaque que, em 1972, Rangel de Lima dá forma de letra à clara separação entre os dois modelos de mulheres, intitulando a sua coluna de "Senhoras e mulheres". recursos e afetos do lar, daí competir-lhe governar os serviçais e prover o bem-estar e a felicidade do marido e filhos, pelo que é denominada de "dona" (sinónimo de "senhora da casa"), esta é a executora dos serviços que garantem o sustento (cozinhar) e os cuidados com a família (limpar a casa e tratar das roupas), pelo que vem apelidada de "doméstica" ${ }^{146}$. É nessa linha de obras de pedagogia sobre economia doméstica que se insere a nossa obra, que o editor claramente apelida de "repositorio de receitas muito úteis no lar doméstico" (p. vII), com o fim de "instruir a família na proveitosa arte de cozinha portugueza" (p. viII).

Tanto num caso, como no outro, ser mulher corresponde a um estado e condição de total dedicação e disponibilidade para servir e satisfazer os gostos, no seio familiar, dos seus "entes mais queridos"147. Transpondo para fora das portas da vida privada do lar esta missão abnegada, que a moral vigente da época elevara a verdadeiro ícone estereotipado da condição feminina, verificamos que é sobretudo no seio das iniciativas promovidas pela Igreja que a boa dona de casa está moralmente autorizada a intervir no espaço público e social externo. No geral esperava-se dela uma vida recatada, de acordo com a qual as suas poucas e breves aparições em público se resumiam às idas à missa e a outras iniciativas religiosas ou cívicas de índole filantrópica. Neste domínio, coube-lhe sempre um papel muito ativo e dinamizador das mais diversas obras de caridade. Oferecer os seus receituários para uma obra coletiva destinada a angariar fundos para a reconstrução de um templo emblemático da paróquia é, seguramente, uma das várias demonstrações que espelham esse status quo feminino burguês, como esclarece Maria Lúcia de Brito Moura, que distingue a mulher do século XIX-inícios do XX com o atributo de "alma da Igreja"148.

146 A distinção entre "boa dona de casa" e "boa doméstica" é uma criação da burguesia do século xıx, que, como alerta Maria Teresa Valente Pinto (apud Vaquinhas 2011: 199), diferencia as mulheres das classes médias das pertencentes às classes populares.

147 Vaquinhas 2011: 200, citando Costa 1925: VII.

148 Moura 2011: 296. Como bem sublinha e demonstra a historiadora nesse seu estudo, numa sociedade oitocentista onde o anticlericalismo grassava entre os homens burgueses, as suas esposas assumiam-se como baluartes do catolicismo resistente e que procura recuperar, através da ação catequizadora das esposas, 
Convém ainda assinalar que, como é próprio deste período de mudança e transformações, no que se refere ao livro Cosinha Portugueza, ele ilustra bem o paradoxo da condição feminina: dividida entre o espartilho das virtudes sociais e religiosas da discrição, modéstia, timidez e pudor (que a tornava "prisioneira" do espaço privado ${ }^{149}$ ) e a intervenção em domínios vários do espaço público (como as obras de beneficência e a edição literária). No entanto, há que notar que o anonimato a que são confinadas as autoras/transmissoras das receitas mais não é do que o resultado da imposição da moral católica e dos preceitos de civilidade feminina do recato e da discrição - extensível aos gestos de grandeza. Da mulher esperava-se, em todos os contextos, a abnegação da fama pública, palco reservado ao sexo masculino.

\section{O discurso culinário nacionalista na Cosinha}

\section{Portugueza}

Em artigo de 2007, José Manuel Sobral analisa o contributo decisivo do Estado Novo (1933-1974) para a afirmação do nacionalismo culinário em Portugal ${ }^{150}$. O que o estudo da Cozinha Portugueza nos permite explorar é que, dentro de um mesmo espírito de exaltação patriótica, foi no início da última década da Monarquia Constitucional (1820-1910), mais precisamente nos alvores do século xx, que a imprensa portuguesa editou o primeiro livro de culinária nacional ${ }^{151}$. Aliás o compilador

os maridos transviados e manter a criação dos filhos de acordo com os preceitos da Santa Madre Igreja.

149 Vaquinhas 2000: 16.

150 Sobral 2007. Desenvolve a questão do nacionalismo culinário posteriormente, cf. Sobral 2014a e 2014b.

151 Note-se que, nesta matéria, o Brasil se antecipa à antiga metrópole, ao editar algures entre 1874-1888 o Cozinbeiro Nacional, obra anónima, mas que algumas edições atribuem a Paulo Salles. A sétima e última edição data de 1910. Como bem observa Carlos Alberto Dória, do ponto de vista histórico esta "necessidade" de afirmação de uma culinária nacional brasileira deve ser entendida no contexto de um movimento cultural mais amplo. Este livro e o primeiro do género impresso no Brasil (Cozinheiro Imperial, 1840) "representam um esforço de nacionalização do saber culinário e são, por isso mesmo, o marco da obra, na folha de rosto, atribui um subtítulo à coleção de receitas bem explícito do ufanismo nacionalista que motiva a obra: Arte Culinária Nacional. Este livro, apesar de exibir no seu subtítulo o adjetivo nacional, não se insere tanto numa corrente impulsionada por forças políticas de autodeterminação a todos os níveis (incluso o alimentar) ${ }^{152}$, mas sim por agentes culturais de ordem social e religiosa.

Nas breves páginas (IX-XII), reproduzidas da 1. edição, de fundamentação da "utilidade" (a que chamaríamos interesse social) da publicação do tipo de obra em questão e apresentação da sua estrutura formal, o editor fornece indicações que nos permitem perceber os princípios que, à luz da mentalidade da época, definem uma identidade culinária nacional específica - no caso vertente a portuguesa.

Como em qualquer processo de tomada de consciência de identidade, também no domínio alimentar e gastronómico a génese do processo radica sempre no confronto com o 'outro'153. Não nos surpreendemos, por isso, que seja o predomínio quase generalizado, no panorama editorial do país, de livros de cozinha com "receitas e acepipes estrangeiros" o primeiro argumento evocado pelo editor para justificar a obra de pendor nacionalista que coordena. Ou seja, o livro que edita é apresentado como um ato consciente de rotura com a moda (sobretudo francesa) instalada dos "floreados pratos à la maître d’hotel e à Pompadour" 154 .

de formação de um pensamento autóctone sobre o comer entre a elite agrária e os nascentes setores urbanos do país" (Dória 2009: 8).

152 Como chama a atenção Dória, esse é o caso de países de unificação tardia, como a Itália, ou de sociedades coloniais, que vão buscar raízes alimentares pré-conquista para definirem uma identidade diferenciadora do colonizador, caso do México (2009: 9-10).

153 Note-se que o editor reflete, nas palavras que usa, a perfeita consciência de que a ingestão de comida não se resume à satisfação das necessidades básicas de sobrevivência (ao que se denominaria de 'alimentação'), mas permite ao indivíduo fruir do prazer gastronómico (o que em linguagem do autor corresponde a "atender ao dom do gosto ou paladar que Deus lhe concedeu”, p. IX).

154 Sobre a influência de receituários de origem estrangeira em obras de autores portugueses (desde o primeiro livro de cozinha português, ainda manuscrito, conhecido por Livro de Cozinba da Infanta D. Maria, passando pelo primeiro livro impresso, de Domingos Rodrigues, em 1680, e seus sucessores até aos inícios do século xx), vd. Braga 2006. 
Pelo que, em primeira linha, o patriotismo culinário a que exorta as famílias portuguesas em geral ${ }^{155}$ (naturalmente através das grandes mentoras dessa esfera privada, as boas donas de casa, a quem dedica o livro) é uma espécie de 'xenofobia gastronómica'!

Além da afirmação da identidade pela diferença (espelhada no confronto entre nacional e estrangeiro), detetamos uma argumentação de promoção do património culinário autóctone assente em critérios de natureza bem diversa, mas que, quando interligados, denunciam a superioridade da arte culinária nacional portuguesa face às suas congéneres. São cinco as ordens de razões para as "comidas nacionais" (p. $\mathrm{x}$ ) serem mais proveitosas e úteis que as "exquisitas, importadas do estrangeiro" (ibidem): razões económicas, sociais, higiénicas, sentimentais e técnicas. Pratos da "cosinha portugueza de nossos avós" (ibidem) têm ingredientes e processos de confeção mais simples, o que desde logo advoga a favor das finanças domésticas, já que promove uma cozinha acessível à "bolsa parca da grande maioria" (p. IX). Estamos, pela primeira vez, perante um movimento que se vai acentuar com o decurso subsequente das duas grandes guerras mundiais, a "democratização" da cozinha, com livros em que é clara a preocupação em publicar literatura culinária acessível às bolsas mais modestas ou remediadas. Combater o elitismo de bem comer é um desígnio que a memória gastronómica dos antepassados pode ajudar a alcançar, já que é "simples, mas substancial e boa" (p. x). Saúde, bem-estar e gastronomia casam-se perfeitamente na Cosinba portugueza. É interessante notar a consciência de que há uma memória gustativa, que se transmite de geração em geração. Quanto aos gostos da moda culinária importada, que poderiam causar estranheza, esses, como insiste o editor, eram pouco higiénicos (leia-se salutares). Sobre essas comidas sem tradição vernácula escreve: "nem são próprias do nosso paladar, nem dão garantia suficiente de constante saude" (ibidem). Podemos

155 Leia-se: "Sejamos também patriotas nesta especialidade, que tanto nos interessa” (p. x). resumir o confronto de identificação diferenciadora entre a cozinha nacional e a estrangeira nos seguintes pares de opostos: economia/despesismo, democratização/elitismo, saúde/doença, simplicidade/sofisticação, património/importação.

No entanto, tendo chegado ao compilador do livro receitas que são "notas" de "muito respeitaveis Senhoras", elas próprias conhecedoras dos livros e da cozinha "estrangeirada" que era servida nos banquetes que ofereciam e frequentavam, não é de surpreender que tal receituário já viesse naturalmente contaminado por essa capa de cultura. Houve, por conseguinte, necessidade de "banir por completo os nomes estrangeirados, que já andam por enfeite em receitas que são nossas”. O fenómeno de contaminação, de que se queixa o editor e que o levou por vezes a ter de "aportuguesar nomes estranhos" com que se deparou, é uma realidade que contemporaneamente continua muito presente (mesmo na descrição de receituário tradicional).

Em suma, esta obra genesíaca da cozinha nacional na literatura culinária portuguesa apresenta-se revolucionária no que tem de resgate de património gastronómico, mas também de linguagem técnica própria.

\section{4. "Iguarias académicas": a presença da "culinária HONORÍFICA" NA FORMAÇÃO DO PATRIMÓNIO ALIMENTAR NACIONAL}

Composta por 795 receitas, repartidas por 13 categorias distintas de preparados, a Cosinha Portugueza, na sua 2. edição, invertendo a disposição inicial, passa os "apêndices" para “preliminares". Já acima comentámos que essa modificação é responsável por confrontar o leitor, antes de mais, com a missão catequética e moralizadora dos bons costumes apregoados pelos ensinamentos da doutrina cristã. Tratando-se de um livro propriedade de uma instituição de caridade religiosa, o conjunto de "reflexões" sobre o "modo de bem viver", longamente apresentado (pp. XV-XXVIII), serve a missão doutrinária que inspira todas as 
suas iniciativas. Sem entrarmos em grande detalhe, destacamos as principais lições transmitidas:

- a decadência moral que grassa a vida contemporânea decorre do desprezo pelos três alicerces do "viver honestamente": os preceitos do Evangelho, a conduta virtuosa em sociedade, os deveres familiares (resumidos, na p. XVIII, na tríade "Deus, pátria e família”, que havia de servir de estandarte às políticas moralizadoras do Estado Novo);

- educar as crianças (pois, como se depreende, são elas os futuros adultos e dirigentes do país) na observância das virtudes morais, mais importantes que a instrução, cabendo aos pais em geral um papel firme e empenhado na escolha do mais conveniente para elas;

- elogio do trabalho e da poupança, garantes de uma vida modesta e feliz;

- valores que fazem da mulher uma "senhora": ser uma boa dona de casa ${ }^{156}$ inteiramente dedicada aos seus entes queridos $^{157}$.

A este ponto seguem-se mais cinco itens de preceitos, de ordem dietética prática, uma vez que cobrem domínios que, desde a criação da ciência por Hipócrates no século v a. C., não mais foram esquecidos nos discursos higienistas posteriores. $\mathrm{O}$ 'modo de vida' saudável subjacente aos ensinamentos de seguida apresentados contempla, nessa linha clássica fundadora, a habitação (lugar - com especial referência ao ar, à luminosidade e ao ambiente natural envolvente, bem como à residência, pp. XXIX-XXXIV), as águas (para beber e os banhos, pp. Xxxv-Xxxvi), a comida (quer os alimentos sólidos, quer as bebidas, com referência a propriedades

156 Pelo que o autor, a propósito da educação, aconselha "estimular e fazer por interessar o espirito das meninas em tudo o que diga respeito á economia doméstica; nisto está o principal valor de uma mulher”, p. XIx.

157 Como se lê na p. xx: “- ter a mulher respeitosa amizade a seu marido, dedicada e extremosa sempre, e principalmente quando o veja mortificado pela lucta da vida; a felicidade da mulher está em ser bondosa, alegre e trabalhadeira, sendo a sua corôa de gloria amar seu marido e seus filhos" (sublinhado nosso). e ao equilíbrio que os métodos de confeção lhes imprimem ${ }^{158}$, para além dos condicionalismos que o clima, a estação do ano, a idade, o sexo, a constituição corpórea e o trabalho impõem a cada regime alimentar individual ${ }^{159}$, pp. XXXVII-XLVIII) e o vestuário (pp. XLIX-LXIV). Uma parte comum a todas estas rubricas e que denuncia a marca de uma tradição que encontramos presente nos livros de culinária portugueses precedentes (sobretudo os manuscritos conventuais) é a presença, no termo de cada um desses apartados, de "segredos", i. e. "receitas" para resolver dificuldades mais comuns em cada sector (purificar o ar das habitações e a água de beber, tirar nódoas, conservar alimentos, eliminar pragas, etc.).

Como seria de prever, o grosso da obra reúne as quase oitocentas receitas compiladas pelo editor, tão crente no uso recorrente que as suas leitoras lhe dariam que reserva as folhas finais para páginas pautadas de linhas, destinadas a "notas" de dois tipos. Pensando (julgamos nós) na eventualidade de uma nova edição, que muito ganharia com as sugestões de quem tivesse comprado e experimentado o receituário do livro, aí se encontram duas páginas para retificações (pp. 251 sq.) e quatro para novas receitas (pp. 253-256), escritas pelo punho das suas leitoras.

Sendo a primeira obra assumidamente de recolha de património culinário português, é necessário começar por esclarecer que, tanto do ponto de vista da estrutura formal, como da semântica do conceito 'nacional', o leitor tem que se despir de ideias hoje estabelecidas como características de um livro desse tipo. Como temos insistido, a Cosinha Portugueza vem na linha editorial que a antecede e com ela convive, ainda que assuma um propósito claro de inovação ao conceber-se como obra "exclusivamente" empenhada na recuperação e divulgação da "cozinha dos avós". Não estranhemos, por isso, que siga a apresentação das receitas não por regiões do país (como hoje sucede), mas por pratos e serviços, na ordem em que eram levados à mesa: sopas e purés

158 Assim, as carnes magras devem ser cozinhadas com substâncias gordas, pex. (p. Xxxix).

159 Havendo mesmo uma chamada de atenção para os cuidados especiais que se deve dar à alimentação dos convalescentes (p. XL). 
(pp. 1-12), legumes e hortaliças (pp. 13-18), carnes diversas (pp. 19-48), croquetes e almôndegas (pp. 49-54), peixes diversos (pp. 55-82), molhos diversos (pp. 83-90), massas e entremeios (pp. 91-96), pastéis, tortas e empadas (pp. 87-108), ovos e omeletas (pp. 109-116), saladas diversas (pp. 117-118), doces de sobremesa (pp. 119-184), compotas e conservas de fruta (pp. 185-202) e doces de chá (pp. 203-246).

Quanto ao entendimento de 'nacional' e 'português' convém ter presente que, além da dimensão geográfica e político-administrativa, para o caso de um domínio cultural como é o da alimentação, em primeira instância (ou seja no período da vivência do sujeito no seio da família) os níveis primordiais de identidade são os hábitos e gostos do agregado familiar e do indivíduo. É, por conseguinte, natural que se tome por sinónimo de 'português/ nacional' a "culinária dos afetos", aquela que diretamente se diz (muitas vezes no próprio título) ter sido transmitida por familiares e amigos. No caso da obra presente, embora possamos suspeitar que muitas das receitas contempladas teriam sido transmitidas às Senhoras que as forneceram ao editor no seio do respetivo agregado familiar (sobretudo o feminino), não há como prová-lo. Outro nível de "portugalidade" é a localidade em que se vive, a que se associam práticas culinárias e comidas. Ampliando o espectro geográfico, as regiões que constituem um país também veem associar-se-lhes uma culinária própria. O patamar mais abrangente e unificador dessas variedades familiares, locais e regionais que integram o património culinário de um coletivo passível de se identificar com a categorização político-administrativa de um país é a 'culinária nacional'.

No estudo presente restringimos o nosso campo de análise ao receituário cujos títulos exibem um adjetivo ou nome próprio topográfico. Uma vez que a obra foi publicada em Coimbra, considerámos ainda os casos em que a "cozinha local" se especializa em "culinária honorífica", prestando homenagem à mais expressiva comunidade da cidade: a Universidade de Coimbra. Esclareça-se, desde já, que atribuir a determinados pratos "títulos" evocativos da Academia constitui uma prática que vem na linha muito comum em livros de cozinha desde a Antiguidade (romana) ${ }^{160}$ de homenagear não só figuras individuais (públicas ou privadas), mas também grupos (alguns dos mais comuns exemplos, também, exibidos neste receituário de 1902, são: 'burgueza', 'lavradora', 'militar', 'nobreza', 'camponeza', 'afidalgada', 'diplomata', 'aristocrata', 'freira', 'franciscano', etc.).

Consideremos, agora, a representatividade destas receitas declaradamente nacionais relativamente ao corpus total da obra. Primeira observação: trata-se de uma tipologia transversal à quase totalidade das rubricas (havendo só uma que não a contempla, a dos "legumes e hortaliças"). Mais, reforça-se a ideia de que é sobretudo na doçaria que o património alimentar português revela maior "orgulho patriótico", visto que, de um total de 72 receitas com títulos topográficos e honoríficos de cozinha portuguesa, 29 aparecem nas rubricas de salgados e 43 nas dos doces.

Em termos de mapeamento geográfico do receituário, torna-se evidente que o local de publicação da obra (Coimbra) e o tratar-se de uma obra coletiva composta de contributos de senhoras a residirem ou com ligação à cidade terão contribuído, igualmente, para um nítido predomínio de receitas originárias das regiões limítrofes e a norte (interior e litoral) da cidade: onde se incluem sete de Coimbra (duas com o nome da cidade e cinco evocativas da Universidade de Coimbra), duas de zonas próximas (Semide e Verride), 14 de cidades na zona setentrional (três de Viseu, três do Porto, uma de: Guarda, Arouca, Braga, Aveiro, Pinhel, Valença, Lamego e Covilhã) e seis de regiões que englobam estes mesmos lugares (duas do Minho, três da Beira ou “beiroas”, uma do norte). No entanto as outras duas grandes regiões do continente, bem como as ilhas atlânticas não ficam de fora, sendo de assinalar o destaque que merece a culinária alentejana (em termos regionais a mais expressiva de todas, com seis receitas com a terminologia da região no título, a que se têm de juntar três de cidades além Tejo: Castelo Branco, Arronches e Niza). Considere-se ainda que só há

160 Apenas dois exemplos retirados do Livro de cozinha de Apício, ambos com títulos em que se homenageiam imperadores: "Ervilhas ou favas à moda de Vitélio" (receita 194) e "Puré à moda de Cómodo" (receita 198). Trad. portuguesa de Ornellas e Castro 2015. 
uma receita alusiva a Lisboa. Das ilhas aparecem duas referências aos Açores (mais precisamente uma com o topónimo de uma ilha, a Terceira, e outra com o de Ribeira Grande, localidade da ilha de São Miguel), duas à Madeira, a que se devem adicionar ainda duas menções indiscriminadas a "ilha" e "ilhas".

Não esquecer que as alusões topográficas nos títulos de receitas proporcionam aos consumidores (quando oriundos de localidades diversos daquelas) o acesso ao "típico"161 (real, presumido ou inventado) e uma ilusória viagem aos (ditos) locais de origem. Quer isto dizer que um prato (assim como um produto) ganha interesse junto de quem come, soma valor e qualidade em ser dado como típico de um lugar. Mais, esse potencial valorativo aumenta ainda mais na medida em que a associação do "gosto" a um "lugar" substitui uma viagem (real) do consumidor a esses destinos ${ }^{162}$.

Guardámos para o fim os quantitativos absolutos e parcelares das receitas de expressão nacional. Num total de 12, deparamos com 10 “à portuguesa” e duas com o adjetivo "nacional”, sendo de notar que, em termos relativos, se verifica uma adequação entre a terminologia nacional mais usada e o nome da obra (Cosinha Portugueza)!

Mas o foco da nossa atenção vai recair sobre cinco receitas cujos títulos constituem um claro elogio à comunidade universitária da cidade em que se edita o primeiro livro português de culinária nacional. Daí que nos tenhamos proposto agrupá-las sob uma denominação comum: "Iguarias Académicas".

Como seria de esperar, não há que procurar nos ingredientes nem nos métodos de preparo nenhum elemento identitário "académico". O mais comum fundamento da "culinária honorífica"

161 "Típico" define-se pela ligação estreita entre um determinado "lugar" (tomado na aceção mais ampla de sítio geográfico e de condições naturais e artificiais de produção próprias desse lugar, e que os franceses exprimem através do substantivo terroir) e "gosto" (no sentido de 'sabor'). Sobre este conceito, vd. Trubek (2008: 18-53). Vários estudiosos têm procedido ao estudo do desenvolvimento histórico desta noção, que fazem remontar à Baixa Idade Média (Capatti-Montanari 1999: VII-XVI), no caso italiano, e ao século XVIII, em França (Csergo 2001; Meyzie 2007), sendo particularmente pertinente nas estratégias de "marketing emocional" exercidas pela indústria agro-alimentar nos inícios do século xx (Ceccarelli-Grandi-Magagnoli 2010).

162 Transferimos para as receitas esse efeito de substituição sugerido por Ceccarelli-Grandi-Magagnoli (2010: 53) para as designações de locais de origem aplicadas a produtos. é o de denunciar o gosto e hábito de consumo do homenageado ou de lhe reconhecer distinção, intitulando uma receita com o seu nome. Numa cidade onde os estudantes universitários, os futuros doutores, são uma das maiores forças vivas da sua dinâmica e o maior coletivo de bocas a alimentar, não é de estranhar que em sua honra tenha surgido um prato. Não será, julgamos, improvável que os alunos apreciassem e consumissem uma iguaria rápida e de confeção simples, tão enraizada na cozinha portuguesa, a omoleta, que neste livro vem identificada como omoleta de estudante (p. 116).

Mas as homenagens, muitas das vezes, não servem, como no caso precedente, para distinguir o 'comum', mas para relevar o 'invulgar'. Esse terá sido o caso de uma das duas receitas de bacalhau com denominação académica no título: o bacalhau à doutora (p. 60). A frequência das aulas da universidade por mulheres era um fenómeno recente na Europa (meados do século xix) e ainda mais em Portugal. Entre os anos letivos de 1891/92 e 1895/96, a Universidade de Coimbra contou apenas com uma estudante inscrita, Domitila de Carvalho. Até à queda da monarquia, a Academia assistiu a um progressivo, mas diminuto, ingresso de jovens do sexo feminino, sendo por alturas da publicação deste livro de cozinha, mais precisamente em 1901, o ano em que o número foi mais elevado (no total de oito) ${ }^{163}$. Se para a sua boa receção por parte dos colegas e de (alguns) professores ${ }^{164}$ já possuíamos confirmação histórica, deparamos com mais um singelo sinal da admiração que despertaram através da inclusão de uma receita em sua homenagem na Cosinha Portugueza de 1902.

Mas a vida académica não se resumia (nesses finais do século XIX e inícios do Xx, tal como ainda hoje sucede) à frequência dos cursos. Havia um ambiente cultural musical particularmente ativo e que muito se fazia sentir na cidade, a então denominada “Academia Musical de Coimbra”, fundada em 1888, homóloga de

163 Cf. Prata 2002: 81-85, Gomes 1987: 9-23.

164 Como bem observa Prata (2002: 83), entre os docentes da época estava Bernardino Machado, defensor da igualdade de educação para homens e mulheres. Aliás, na conferência de encerramento do "Congresso Pedagógico Hispano-Português-Americano" (Madrid 1892), afirmara publicamente esse direito (cf. Machado 2009: 445). 
outras estudantinas europeias, e cuja designação veio a evoluir para "Tuna Académica da Universidade de Coimbra". Além dos numerosos saraus realizados na cidade, a tuna percorreu desde as primeiras décadas da sua existência as principais cidades portuguesas, contando ainda com frequentes deslocações a cidades da vizinha Espanha ${ }^{165}$. A homenagem a estes músicos que levavam a todo o Portugal e além-fronteiras o nome da sua universidade assumiu no nosso receituário a forma de dois pratos, um de carne e outro de peixe: o coelho á estudantina (p. 47) e o bacalbau á estudantina (p. 60).

O menu académico completa-se com um doce, seco e fácil de preparar e, de acordo com a rubrica em que vem incluído, adequado para acompanhar o chá. Este é uma homenagem à universidade no seu todo, conforme sugere o nome biscoitos académicos (p. 228).

Em suma, o presente estudo permite concluir que, desde inícios do século xx, a Alma Mater Conimbricensio faz parte da literatura culinária de pendor nacionalista. O que o percurso hermenêutico por este livro de culinária nos dá a perceber é que o conceito de "culinária nacional" é sempre uma "representação" e nunca uma "realidade". Dito por outras palavras, estamos perante uma construção forjada que espelha um desígnio de uniformização e comunhão de cultura culinária. Na base desse impulso agregador encontramos explicações tanto de ordem política (laica ou religiosa) como emocional. Verificámos que, numa obra autodenominada de culinária nacional, se intersectam distintas cozinhas, todas reconhecidas como portadoras ou promotoras da identidade portuguesa: a "cozinha dos territórios" (local, regional e nacional), a "cozinha honorífica" e a "cozinha dos afetos".

Em conclusão, percebemos que o espectro simbólico do nacional abarca tanto o coletivo como o individual, tanto o que se herda, como o que se transmite (aos familiares e vindouros), resultando num diálogo constante entre o público e o privado, o grupo e o sujeito.

165 Com destaque para a digressão pela região da Galiza (em 1898) e as deslocações a Salamanca e Valladolid (1900), bem como a Lugo e Ourense (1902). Cf. Soares 1985: pp. relativas aos anos de 1901 e 1902.

\section{BIBLIOGRAFIA}

Alves, D. (1992), Era Tormed e amanhecia - Dicionário Gastronómico Cultural de Eça de Queiroz. Lisboa.

Araújo, Frei António de Sousa (1995), “O Pão dos Pobres de santo António", Almanaque de Santo António, 240-244.

Berrini, B. (1995), Comer e Beber com Eça de Queiroz. Rio de Janeiro.

Berrini, B., Modesto, M. L. (2014), Comer e Beber com Eça de Queiroz. Lisboa.

Braga, I. D. (2006), "Influências estrangeiras nos livros de cozinha portuguese (séculos XVI-XIX): alguns problemas de análise”, in Estudos em homenagem ao Professor Doutor José Marques. Faculdade de Letras da Universidade do Porto, vol 2., 237-247.

Bower, A. (1997), "Cooking up Stories: Narrative Elements in Community Cookbooks", in A. Bower (ed.), Reciped for Reading: Community Cookbookd, Storied, Historied. Amhurst, 29-51.

Capatti, A., Montanari, M. (1999), La cucina italiana. Storia di una cultura. Roma, Bari.

Ceccarelli, G., Grandi, A., Magagnoli, S. (2010), “The 'taste' of 'typicality'”, Food es History 8.2: 45-76.

Costa, Emília de Sousa (1925), Na sociedade e na familia. Regras de convivência - Obrigações sociais - Usos mundanos - Notas íntimas. Lisboa. Livraria Clássica. Editora de A. M. Teixeira \& C. ${ }^{a}$ (Filhos).

Csergo, J. (2001), “O surgimento das cozinhas regionais”, in J.-L. Flandrin, M. Motanari (eds.), História da Alimentação. Vol. II. Lisboa, 383-398 (ed. original francesa: Histoire de l'Alimentation. Paris, 1996).

Dória, C. A. (2009), “Cozinha nacional antes da Feijoada”, in Cozinheiro Nacional. Coleção das melhores receitas das cozinhas brasileira e européias. Prefácio de Carlos Alberto Dória, revisão Geraldo Gerson de Souza e Maria Cristina Marques. Ateliê Editorial, Editora Senac São Paulo, 1. ${ }^{a}$ ed. 2008, 7-26.

Gomes, J. Ferreira (1987), A mulher na Universidade de Coimbra. Livraria Almedina, Coimbra. 
Gomes, J. Pinharanda (2007-2008), “Pias Uniões em Portugal: subsídio monográfico”, Lusitania Sacra, 2. ${ }^{a}$ série, 19-20: 471-482.

Leong-Salobir (2015), "Spreading the Word: Using Cookbooks and colonial memoires to examine the foodways of British Colonies in Asia”, in C. Helstosky (ed.), The Routledge Food History. New York, 131-155.

Lynne, I. (1981), “The Compiled Cookbook as Foodways Autobiography', Western Folklore 40.1: 104-114.

Machado, Bernardino (2009), Bernardino Macbado. Obras II. Pedagogia, tomo 1. Edições Humus.

Meyzie, Ph. (2007), La table du Sud-Ouest et l'émergence des cuisines régionales. Rennes.

Moura, M. L. de B. (2011), "Sensibilidade religiosa e devoção doméstica: entre o «temor de Deus» e o «amor de Deus»", in Irene Vaquinhas (coord.) (2011), História da Vida Privada em Portugal. A Época Contemporânea. Direcção de José Mattoso. Círculo de Leitores. Lisboa, 290-321.

Ornellas e Castro, I. (2015), O Livro de Cozinba de Apício. Um breviário do gosto imperial. Lisboa.

Peixinho, A. T. (2016), “Estética alimentar queirosiana: notas gastronómicas na obra de Eça de Queirós”, in Pinheiro, J., Soares, C. (eds.), Patrimónios Alimentares J’Aquém e Além-mar. Coimbra, 199-218.

Pilcher, J. (1997), "Recipes for Patria: Cuisine, Gender, and Nation in Nineteenth-century Mexico", in A. Bower (ed.), Recipes for Reading: Community Cookbooks, Storied, Histories. Amhurst, 200-215.

Pinto, M. T. V. (2008), A formação profissional das mulberes no Ensino Industrial Público (1884-1910), realidades e representações. Lisboa, Universidade Aberta (dissertação de doutoramento).

Prata, M. A. C. (2002), Academia de Coimbra (1880-1926). Contributo para a sua História. Imprensa da Universidade de Coimbra, Coimbra.

Sameiro, P. (2011), "Savings Banks in Portugal: Origins and Attributes", ESBG Perspectives 63: 49-56.
Soares, J. A. (1985), Saudaded de Coimbra (1901-1916). Livraria Almedina, Coimbra.

Scott, N. (1992), “Juana Manuela Gorriti’s Cocina Ecléctica: Recipes as Feminine Discourse", Hispania 75.2: 310-314.

Sobral, J.M. (2007), "Nacionalismo, culinária e classe: a cozinha portuguesa da obscuridade à consagração (séculos XIX-XX)", Revista Centro de Estudos Rurais - RURIS 1.2: 13-52.

Sobral, J. M. (2014a), "The country, the nation, and the region in representations of Portuguese food and cuisine”, in Domingos, N., Sobral, J. M., West, H. (eds.), Food between the country and the city: ethnographies of a changing global foodscape. London, 145-160.

Sobral, J. M. (2014b), "The high and the low in the making of a Portuguese national cuisine in the nineteenth and twentieth centuries", in Klein, J. A., Murcott, A. (eds.), Food consumption in global perspective: essays in the anthropology of food in bonour of Jack Goody. Basingstoke, 108-134.

Trubek, A. B. (2008), The Taste of Place: a Cultural Journey into Terroir Berkeley, Los Angeles.

Vaquinhas, I. (2000), Senhoras e mulberes na sociedade do séc. XIX. Colibri Lisboa, 2. ${ }^{a}$ ed. 2011.

Vaquinhas, I. (2005), Ao mulberes no Mundo Contemporâneo: História Comparada. Coimbra.

Vaquinhas, I. (coord.) (2011), História da Vida Privada em Portugal. A Época Contemporânea. Direcção de José Mattoso. Círculo de Leitores. Lisboa.

Vilela, A. L. (2010), “Le corps et le roman: l'allusion culinaire et la représentation des repas das O๖ Maiad, de Eça de Queirós”, in Buschinger, D. (ed.), Banquets et convivialité. Actes du colloque iternational des 3, 4 et 5 mars à la Maison de la Culture d'Amiens, $173-178$. 